Kong. Res. J. 2(2) : 37-39, 2015

ISSN 2349-2694

Kongunadu Arts and Science College, Coimbatore.

\title{
FUZZY SHORTEST ROUTE ALGORITHM FOR TELEPHONE LINE CONNECTION USING THE LC-MST ALGORITHM
}

\author{
Vijayalakshmi, D. and R. Kalaivani* \\ Department of Mathematics, Kongunadu Arts \& Science College, Coimbatore-641 029, India. \\ *E.mail: kalaivanirm@yahoo.com
}

\begin{abstract}
In computer science, there are many algorithms that finds a minimum spanning tree for a connected weighted undirected fuzzy graph. The minimum length (or cost) spanning tree problem is one of the nicest and simplest problems in network optimization, and it has a wide variety of applications. The problem is to find a minimum cost (or length) spanning tree in G. Applications include the design of various types of distribution networks in which the nodes represent cities, centers etc.; and edges represent communication links (fiber glass phone lines, data transmission lines, cable TV lines, etc.), high voltage power transmission lines, natural gas or crude oil pipelines, water pipelines, highways, etc. The objective is to design a network that connects all the nodes using the minimum length of cable or pipe or other resource in this paper we find the solution to the problem is to minimize the amount of new telephone line connection using matrix algorithm with fuzzy graph.
\end{abstract}

Keywords: Spanning tree, minimum spanning tree, fuzzy graph, Matrix algorithm.

\section{INTRODUCTION}

A minimum cost of the fuzzy spanning tree is spanning tree, but it has weight or length associated with the edges and total weight of the tree is minimum. A fuzzy tree for that graph would be a subset of those paths that has no cycles but still connects to every vertex. There might be several spanning trees possible. A minimum fuzzy tree would be one with the lowest total cost. A less obvious application is that the minimum fuzzy spanning tree can be used to approximately solve the traveling salesman problem.

In this paper, we find the solution for the problem, that (A.V.V.M. Sri Pushpam College, (Autonomous), Poondi, Thanjavur District, South India) needs to connect updated intercom lines connecting all the departments using a fuzzy shortest route algorithm. The problem is to minimize the amount of new line using matrix Algorithm with fuzzy graph.

\section{DEFINITION}

Definition 2.1.: A fuzzy graph with $\mathrm{V}$ as the underlying set is a pair G: $(A, \Gamma)$ where $A: V--0,0,1]$ is a fuzzy subset, $\Gamma: \mathrm{VxV}------>[0,1]$ is a fuzzy relation on the fuzzy subset $A$, such that $\Gamma(\mathrm{u}, \mathrm{v}) \leq \mathrm{A}(\mathrm{u}) \cap \mathrm{A}(\mathrm{v})$ for all $\mathrm{u}, \mathrm{v} \in \mathrm{V}$.

Definition 2.2.: A fuzzy Hamiltonian circuit is a circuit that visits every vertex in a fuzzy graph once with no repeats, being a fuzzy Hamiltonian circuits must start and end at the same vertex.

Definition 2.3.: A fuzzy Hamiltonian path is a path that passes through each of the vertices in a fuzzy graph exactly once [Hassan, 2012].

Definition 2.4.: A fuzzy spanning tree is a fuzzy tree which covers all the vertices of a fuzzy graph, [Antony et al, 2013].

NOTE 2.1: Fuzzy tress has no circuits, and it is fine to have vertices

\section{THE LC-MST ALGORITHM}

The aim of the LC-MST algorithm is to find a least-cost tree of a given network. The idea of the algorithm is to read the distance matrix (weight matrix) of a given network and construct a preferred link matrix that contains the set of least-cost links to construct the least-cost minimum spanning tree.

\subsection{Algorithm: Least-Cost Minimum Spanning Tree}

Step 1: Input the distance matrix $D=\left[\mathrm{d}_{\mathrm{ij}}\right]_{\mathrm{nxn}}$ for the weighted graph $G(V, E)$, where $V$ is the set of vertices and $E$ is the set of edges.

Step 2: For all i, j, find the least-cost element (preferred link) in each column j and set the other elements to zero.

Step 3: Construct the preferred link matrix (PLM) by using step 2. 
Step 4: Construct the nodes-set matrix (NSM) by using PLM matrix constructed in step 3 (each element in this matrix contains the node-pairs that correspond to the preferred link in PLM).

Step 5: Combining the node-pairs in step 4 to construct the candidates spanning
Step 6: If there are any duplicating node-pairs, keep one of them, and if there is a set of node-pairs, construct a cycle, remove the one that has the largest cost.

Step 7: Output the least-cost minimum spanning tree.

\begin{tabular}{|c|c|c|c|c|c|c|c|c|c|c|}
\hline- & $\mathrm{x}_{1}$ & $\mathrm{x}_{2}$ & $x_{3}$ & $\mathrm{x}_{4}$ & $\mathrm{x}_{5}$ & $\mathrm{x}_{6}$ & $x_{7}$ & $\mathrm{x}_{8}$ & $\mathrm{X}_{9}$ & $\mathrm{x}_{10}$ \\
\hline $\mathrm{x}_{1}$ & - & 0.37 & 0.1 & 0.22 & 0.07 & 0.17 & 0.25 & 0.28 & 0.24 & 0.35 \\
\hline $\mathrm{x}_{2}$ & 0.37 & - & 0.25 & 0.16 & 0.5 & 0.19 & 0.07 & 0.1 & 0.13 & 0.01 \\
\hline $\mathrm{x}_{3}$ & 0.1 & 0.25 & - & 0.12 & 0.27 & 0.12 & 0.09 & 0.16 & 0.13 & 0.24 \\
\hline $\mathrm{x}_{4}$ & 0.22 & 0.16 & 0.12 & - & 0.43 & 0.03 & 0.04 & 0.08 & 0.02 & 0.15 \\
\hline $\mathrm{X}_{5}$ & 0.07 & 0.5 & 0.27 & 0.43 & - & 0.45 & 0.47 & 0.34 & 0.38 & 0.42 \\
\hline $\mathrm{x}_{6}$ & 0.17 & 0.19 & 0.12 & 0.03 & 0.45 & - & 0.06 & 0.11 & 0.06 & 0.18 \\
\hline $\mathrm{x}_{7}$ & 0.25 & 0.07 & 0.09 & 0.04 & 0.47 & 0.06 & - & 0.11 & 0.08 & 0.11 \\
\hline $\mathrm{X}_{8}$ & 0.28 & 0.1 & 0.16 & 0.08 & 0.34 & 0.11 & 0.11 & - & 0.03 & 0.05 \\
\hline $\mathrm{X}_{9}$ & 0.24 & 0.13 & 0.13 & 0.02 & 0.38 & 0.06 & 0.08 & 0.03 & - & 0.11 \\
\hline $\mathrm{x}_{10}$ & 0.35 & 0.01 & 0.24 & 0.15 & 0.42 & 0.18 & 0.11 & 0.05 & 0.11 & - \\
\hline
\end{tabular}

Fig. 2.1. Distance matrix

\begin{tabular}{|c|c|c|c|c|c|c|c|c|c|c|}
\hline - & $\mathrm{x}_{1}$ & $\mathrm{x}_{2}$ & $\mathrm{x}_{3}$ & $\mathrm{X}_{4}$ & $\mathrm{X}_{5}$ & $\mathrm{x}_{6}$ & $\mathrm{X}_{7}$ & $\mathrm{X}_{8}$ & $\mathrm{X}_{9}$ & $\mathrm{x}_{10}$ \\
\hline $\mathrm{x}_{1}$ & - & 0.37 & 0.1 & 0.22 & 0.07 & 0.17 & 0.25 & 0.28 & 0.24 & 0.35 \\
\hline $\mathrm{x}_{2}$ & 0.37 & - & 0.25 & 0.16 & 0.5 & 0.19 & 0.07 & 0.1 & 0.13 & 0.01 \\
\hline $\mathrm{x}_{3}$ & 0.1 & 0.25 & - & 0.12 & 0.27 & 0.12 & 0.09 & 0.16 & 0.13 & 0.24 \\
\hline $\mathrm{X}_{4}$ & 0.22 & 0.16 & 0.12 & - & 0.43 & 0.03 & 0.04 & 0.08 & 0.02 & 0.15 \\
\hline $\mathrm{X}_{5}$ & 0.07 & 0.5 & 0.27 & 0.43 & - & 0.45 & 0.47 & 0.34 & 0.38 & 0.42 \\
\hline $\mathrm{x}_{6}$ & 0.17 & 0.19 & 0.12 & 0.03 & 0.45 & - & 0.06 & 0.11 & 0.06 & 0.18 \\
\hline $\mathrm{X}_{7}$ & 0.25 & 0.07 & 0.09 & 0.04 & 0.47 & 0.06 & - & 0.11 & 0.08 & 0.11 \\
\hline $\mathrm{X}_{8}$ & 0.28 & 0.1 & 0.16 & 0.08 & 0.34 & 0.11 & 0.11 & - & 0.03 & 0.05 \\
\hline X9 & 0.24 & 0.13 & 0.13 & 0.02 & 0.38 & 0.06 & 0.08 & 0.03 & - & 0.11 \\
\hline $\mathrm{x}_{10}$ & 0.35 & 0.01 & 0.24 & 0.15 & 0.42 & 0.18 & 0.11 & 0.05 & 0.11 & - \\
\hline
\end{tabular}

Fig. 2.2. PLM 


\begin{tabular}{|c|c|c|c|c|c|c|c|c|c|c|}
\hline- & $\mathrm{x}_{1}$ & $\mathrm{x}_{2}$ & $\mathrm{x}_{3}$ & $\mathrm{X}_{4}$ & $\mathrm{x}_{5}$ & $\mathrm{x}_{6}$ & $\mathrm{x}_{7}$ & $\mathrm{x}_{8}$ & X9 & $\mathrm{x}_{10}$ \\
\hline $\mathrm{x}_{1}$ & - & 0 & 0 & 0 & $\left(\mathrm{x}_{1}, \mathrm{x}_{5}\right)$ & 0 & 0 & 0 & 0 & 0 \\
\hline $\mathrm{x}_{2}$ & 0 & - & 0 & 0 & 0 & 0 & 0 & 0 & 0 & $\left(\mathrm{x}_{2}, \mathrm{x}_{10}\right)$ \\
\hline $\mathrm{x}_{3}$ & 0 & 0 & - & 0 & 0 & 0 & 0 & 0 & 0 & 0 \\
\hline $\mathrm{x}_{4}$ & 0 & 0 & 0 & - & 0 & $\left(\mathrm{x}_{4}, \mathrm{x}_{6}\right)$ & $\left(\mathrm{x}_{4}, \mathrm{x}_{7}\right)$ & 0 & $\left(\mathrm{x}_{4}, \mathrm{X}_{9}\right)$ & 0 \\
\hline $\mathrm{x}_{5}$ & $\left(\mathrm{x}_{5}, \mathrm{x}_{1}\right)$ & 0 & 0 & 0 & - & 0 & 0 & 0 & 0 & 0 \\
\hline $\mathrm{x}_{6}$ & 0 & 0 & 0 & 0 & 0 & - & 0 & 0 & 0 & 0 \\
\hline $\mathrm{x}_{7}$ & 0 & 0 & $\left(\mathrm{x}_{7}, \mathrm{x}_{3}\right)$ & 0 & 0 & 0 & - & 0 & 0 & 0 \\
\hline $\mathrm{x}_{8}$ & 0 & 0 & 0 & 0 & 0 & 0 & 0 & - & 0 & 0 \\
\hline $\mathrm{X}_{9}$ & 0 & 0 & 0 & $\left(\mathrm{x}_{9}, \mathrm{X}_{4}\right)$ & 0 & 0 & 0 & $\left(\mathrm{x}_{9}, \mathrm{x}_{8}\right)$ & - & 0 \\
\hline $\mathrm{x}_{10}$ & 0 & $\left(\mathrm{x}_{10}, \mathrm{X}_{2}\right)$ & 0 & 0 & 0 & 0 & 0 & 0 & 0 & - \\
\hline
\end{tabular}

Example: In this example we applied the matrix algorithm to plan and connect an efficient fuzzy route telephone line connection for the problem (Nirmala and Uma, 2012). Consider each department as vertex such as $\mathrm{x}_{1}$-office room, $\mathrm{x}_{2}$ mathematics, $\mathrm{x}_{3}-$ economics, $\mathrm{x}_{4}-$ History, $\mathrm{x}_{5}-$ Computer Science, $\mathrm{x}_{6}-$ Library, $\mathrm{x}_{7}-$ Physics, $\mathrm{x}_{8}-$ Chemistry, $\mathrm{x}_{9}-$ Botany and $\mathrm{x}_{10}-$ Physical education. The distance between them are represented as fuzzy weights matrix shown in the fig.3.8.

In this section, we find the solution for the below matrix the table is taken from (Nirmala and Uma, 2012) needs to connect updated intercom lines connecting all the departments exactly once. The problem is to minimize the amount of new line using Matrix Algorithm with fuzzy graph. The step by step procedure is given below.

The Preferred link matrix PLM (least-cost link matrix) can be constructed from the distance matrix as shown in Fig 2.2.

The corresponding nodes-set matrix NSM is constructed as shown in Fig.2.3.

The set of node-pairs that construct the candidate spanning tree is: $=\left\{\left(\mathrm{x}_{2}, \mathrm{x}_{10}\right)+\left(\mathrm{x}_{4}, \mathrm{X}_{9}\right)+(\right.$ $\left.\left.\mathrm{x}_{8}, \mathrm{x}_{9}\right)+\left(\mathrm{x}_{4}, \mathrm{x}_{6}\right)+\left(\mathrm{x}_{4}, \mathrm{x}_{7}\right)+\left(\mathrm{x}_{1}, \mathrm{x}_{5}\right)+\left(\mathrm{x}_{3}, \mathrm{x}_{7}\right)\right\}$.

The length of the cable

$$
\begin{aligned}
= & \left\{\left(\mathrm{x}_{2}, \mathrm{x}_{10}\right)+\left(\mathrm{x}_{4}, \mathrm{x}_{9}\right)+\left(\mathrm{x}_{8}, \mathrm{x}_{9}\right)+\left(\mathrm{x}_{4}, \mathrm{x}_{6}\right)+\left(\mathrm{x}_{4}, \mathrm{x}_{7}\right)+\left(\mathrm{x}_{1}, \mathrm{x}_{5}\right)\right. \\
& \left.+\left(\mathrm{x}_{3}, \mathrm{x}_{7}\right)\right\} \\
= & 0.01+0.07+0.02+0.04+0.09+0.02+0.03 \\
= & 0.28 .
\end{aligned}
$$

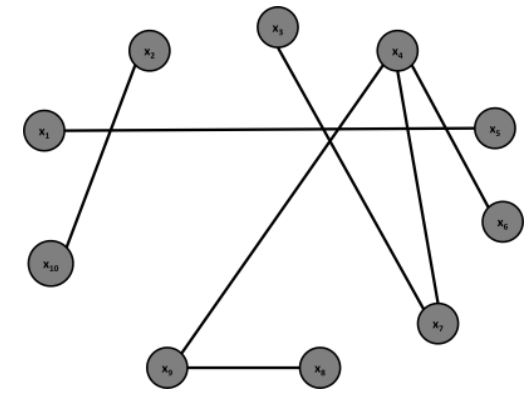

Fig. 2.4. The least cost minimum spanning tree

\section{CONCLUSION}

In this paper we apply the Least-Cost Minimum Spanning Tree for the problem that connecting distances to plan and visit an efficient fuzzy spanning tree route for the intercom land line (phone) to reach it all the department exactly once. So we conclude that Least-Cost Minimum Spanning Tree is the best to adopt for these types of problems.

\section{REFERENCES}

Antony Xavior, D., Florence Isido, D. and V.M.Chtira,

(2013), On Domination In Fuzzy Graphs. IJCA 2: 248250.

Hassan, (2012), An efficient method to solve least cost minimum spanning tree. Comp. Inform. Sci. 24: 101105.

Nirmala, G. and K.Uma, (2012). Fuzzy Shortest Route Algorithm for Telephone Line Connection. IJSRP 2. 